\title{
BMJ Open Trends in national pharmaceutical expenditure on diabetes in Ireland 2011- 2015: a repeated cross-sectional study
}

\author{
Kate N O Neill (D) , ${ }^{1}$ Kathleen E Bennett (iD , ${ }^{2}$ Sheena M Mc Hugh, ${ }^{1}$ \\ Anthony P Fitzgerald, ${ }^{1,3}$ Patricia M Kearney ${ }^{1}$
}

To cite: 0 Neill KN, Bennett KE, Mc Hugh SM, et al. Trends in national pharmaceutica expenditure on diabetes in Ireland 2011-2015: a repeated cross-sectional study. BMJ Open 2020;10:e037382. doi:10.1136/ bmjopen-2020-037382

- Prepublication history and supplemental material for this paper are available online. To view these files, please visit the journal online (http://dx.doi. org/10.1136/bmjopen-2020037382).

Received 30 January 2020

Revised 26 May 2020

Accepted 06 July 2020

Check for updates

(c) Author(s) (or their employer(s)) 2020. Re-use permitted under CC BY-NC. No commercial re-use. See rights and permissions. Published by BMJ.

${ }^{1}$ School of Public Health, University College Cork, Cork, Ireland

${ }^{2}$ Division of Population Health Sciences, Royal College of

Surgeons in Ireland, Dublin, Ireland

${ }^{3}$ Department of Statistics, University College Cork, Cork, Ireland

Correspondence to

Dr Kate N 0 Neill;

kate.oneill@ucc.ie

\section{ABSTRACT}

Objectives To explore trends in pharmaceutical expenditure on diabetes between 2011 and 2015, describing trends in expenditure on blood glucoselowering medications and estimating the effect of costcontainment measures implemented during this time.

Design Repeated cross-sectional study of national pharmacy claims data in Ireland.

Participants Patients' dispensed items used in the treatment or management of diabetes.

Primary and secondary outcomes Total expenditure associated with diabetes was calculated by extracting data on all diabetes-related items dispensed to eligible patients. Costs were categorised into two groups. Diabetes-specific items include items used directly in diabetes treatment (WH0-Anatomical Therapeutic Chemical (ATC): A10, V07, V04) and diabetes-related include all other conditionrelated items (WHO-ATC: B01, C, H04, N03, N06). The impacts of two specific cost-containment measures, co-payments and reference pricing, were assessed using segmented linear regression analyses of interrupted timeseries.

Results Total expenditure varied over the study period, peaking at $€ 216994441$ in 2012 . Expenditure on diabetes-specific items increased steadily by $18 \%$ reaching $€ 153621477$ in 2015 , with blood glucoselowering medications accounting for $73 \%$ of this increase. During the same period, expenditure on diabetes-related items decreased by $32 \%$ to $€ 50835856$. The introduction of reference pricing for atorvastatin in November 2013 resulted in immediate costs savings of $€ 2.4$ million per yearly quarter (level-change $p<0.001$ ).

Conclusions The increasing expenditure on blood glucose-lowering medications negates the effect of recent cost-containment measures, presenting a significant challenge for the provision of diabetes care. Innovative policies are required to ensure high-quality diabetes care can be provided at an equitable, affordable and sustainable rate.

\section{INTRODUCTION}

The global burden of diabetes is a growing challenge for national economies. ${ }^{1-3}$ By 2030, it is estimated that the cost of diabetes will account for $2.2 \%$ of global Gross Domestic Product, increasing from $1.8 \%$ in 2015 . $^{1}$ Direct medical costs account for two-thirds

\section{Strengths and limitations of this study}

This study uses data from a large national pharmacy claims database to analyse trends in pharmaceutical expenditure on diabetes over a 5-year period.

- Cost data from this pharmacy claims database are complete and highly accurate as its primary function is for reimbursement.

- Due to the absence of clinical diagnoses in the database, diabetes diagnosis is defined as having received items used in the management or treatment of diabetes during the study period.

- This study only examines costs of diabetesassociated items according to the definition used by the national reimbursement schemes and thus may underestimate total expenditure attributable to diabetes.

of the costs, ${ }^{1}$ with medication costs identified as the primary driver of increasing medical expenditure on diabetes. ${ }^{4}$ A combination of increasing diabetes prevalence, advancements in clinical guidelines advocating longterm glycaemic control and the upsurge of new expensive medical treatments contributes to the escalating medication costs. ${ }^{3-5}$

As of 2016, there were at least 171 new drug therapies in development for the treatment and management of diabetes and its related complication. ${ }^{6}$ With an emphasis on maintaining glycaemic control, the number of classes of glucose-lowering drugs developed over the past two decades has more than tripled. ${ }^{7}$ Such drug classes include glucagonlike peptide-1 receptor (GLP-1) analogues and sodium-glucose co-transporter 2 (SGLT2) inhibitors. ${ }^{8}$ Novel and innovative treatments are expensive and concern has been raised about whether the benefits of these medications outweigh their significantly higher costs. ${ }^{9}$ While empirical data are scarce, it is predicted these treatments contribute to rising medication costs associated with diabetes and the continued advancement in diabetes-related medical technology will 
likely result in increasing per capita medical expenditure per year. ${ }^{34}$ The most recent American Diabetes Association and European Association for the Study of Diabetes guidelines recommend the use of these newer medications in second-line therapy and although improvements in diabetes care must be promoted, cost-containment measures are necessary to ensure the affordability and sustainability of health systems. ${ }^{710}$

Governments have introduced wide-ranging costcontainment strategies aimed at tackling increasing pharmaceutical expenditure. ${ }^{11}$ Ireland has one of the highest public expenditures on pharmaceuticals among the Organisation for Economic Co-operation and Development (OECD) countries. ${ }^{12}$ Amid concerns over health system sustainability and pressure from the European Union/International Monetary Fund Programme of Financial Support, Ireland introduced an array of costcontainment measures over the last decade. ${ }^{13}$ With the goal of achieving better value for money on pharmaceuticals, such measures include the introduction of a co-payment policy and a model for reference pricing.

We aim to explore national trends in pharmaceutical expenditure on diabetes and related medicines between 2011 and 2015, from the perspective of the healthcare system, with objectives to describe trends in expenditure on blood glucose-lowering medications and to estimate the effect of two cost-containment measures implemented during this time; an increasing co-payment policy and reference pricing.

\section{METHODS}

\section{Reimbursement of medications}

In Ireland, pharmacies are reimbursed for the dispensing of medicines and associated devices through the Health Service Executive- Primary Care Reimbursement Service (HSE-PCRS).${ }^{14}$ HSE-PCRS funds three main community drugs schemes: the General Medical Services (GMS) scheme, the Drugs Payment Scheme (DPS) and the Long-Term Illness (LTI) scheme. ${ }^{14}$ The GMS scheme is a means-tested public health insurance scheme which entitles an individual to prescription medications free of charge. In an effort to curtail expenditure and reduce moral hazard, a flat co-payment was introduced in October 2010 at $€ 0.50$ per item. ${ }^{14}$ This increased to $€ 1.50$ per item in January 2013 and further to $€ 2.50$ per item in December 2013. In 2015, almost $40 \%$ of the population were eligible for the GMS scheme. ${ }^{14}$ The remainder of the population are entitled to governmentsubsidised access to prescription medications through the DPS. Under this scheme, there is a monthly spend threshold of $€ 144$ per household. Once a household reaches this threshold, any additional costs are covered by the DPS and are reimbursed to the pharmacy through the HSE-PCRS. The LTI scheme entitles those with 1 of 16 specific chronic conditions to free prescription medications, independent of income. There are no co-payments for items on the LTI scheme. The HSE-PCRS publishes a core medications list for each of the 16 chronic conditions, listing all the condition-related medications reimbursable under the scheme. ${ }^{15}$ Diabetes is one of these 16 conditions and therefore HSE-PCRS defines a core list of medications reimbursable for the treatment and management of diabetes (see online supplemental table S1). It is possible for a person to be eligible for all three schemes simultaneously.

\section{Data source}

Data from the national HSE-PCRS pharmacy claims database were analysed. While the primary function of the database is for reimbursement, it has previously been used for pharmacoepidemiological and pharmacoeconomic research. ${ }^{14}$ The database contains data on all medications dispensed by community pharmacists under the GMS and LTI schemes. It also contains data on medications reimbursed under the DPS, however, data are only available for items dispensed after the monthly payment threshold is reached. The database contains the date of dispensing, quantity, dose and strength of each medication reimbursed by HSE-PCRS along with information on the ingredient cost, value-added tax (VAT), mark-up and the dispensing fee paid to the pharmacy. Medications are coded using the WHO-Anatomical Therapeutic Chemical (WHO-ATC) classification system. Permission to use the anonymised HSE-PCRS data for research purposes was obtained from the HSE-PCRS.

\section{Participants and prescription items}

A repeated cross-sectional study was conducted whereby we identified all individuals who were dispensed items used in the treatment or management of diabetes for each year of the study period (2011-2015). These items were defined as antidiabetic agents (WHO-ATC: A10), monitoring materials used in self-monitoring of blood glucose, blood ketone and urine analysis (WHO-ATC: V07) or needles and lancets used in these devices and for insulin injection (WHO-ATC: V04). To calculate the total expenditure associated with diabetes from the health system perspective, we then extracted data on all diabetesassociated items dispensed to eligible individuals during each year of the study. We define diabetes-associated items as those listed by the HSE-PCRS as reimbursable for the treatment and management of diabetes. This includes all items used in the treatment of diabetes (WHO-ATC: A10, V07, V04) as well as condition-related items such as cardiovascular system drugs (online supplemental appendix table S1). To explore the costs attributable to diabetes, we categorised items into two groups; diabetes-specific items and diabetes-related items (online supplemental appendix table S1). Diabetes-specific items include items used directly in the treatment of diabetes (WHO-ATC: A10, V07, V04). Diabetes-related items include all other condition-related medications not used directly in the treatment of diabetes (WHO-ATC: B01, C, H04, N03, N06). 


\begin{tabular}{|c|c|c|c|c|c|}
\hline & 2011 & 2012 & 2013 & 2014 & 2015 \\
\hline \multicolumn{6}{|l|}{ All items } \\
\hline GMS & 117654990 & 129172992 & 128203076 & 95225066 & 62766810 \\
\hline LTI & 79535588 & 81389053 & 75334537 & 99676835 & 137721770 \\
\hline DPS & 6902227 & 6432396 & 5164626 & 4377589 & 3968753 \\
\hline Mean cost per item (€) (SD) & $29.47(29.47)$ & $29.34(29.48)$ & $27.66(28.50)$ & $25.69(28.07)$ & $25.40(28.40)$ \\
\hline \multicolumn{6}{|l|}{ Diabetes-specific items } \\
\hline Total expenditure $(€)$ & 129828301 & 140595029 & 141714991 & 144406885 & 153621477 \\
\hline Number of items & 3256314 & 3513731 & 3621232 & 3761657 & 3952042 \\
\hline Mean cost per item (€) (SD) & 39.87 (38.58) & $40.01(38.39)$ & $39.13(36.73)$ & $38.39(35.24)$ & $38.87(34.89)$ \\
\hline Mean cost per item $(€)(S D)$ & $20.24(11.74)$ & $19.68(11.19)$ & $17.07(9.15)$ & $13.75(8.08)$ & $12.41(8.13)$ \\
\hline
\end{tabular}

DPS, Drugs Payment Scheme; GMS, General Medical Services; LTI, Long-Term Illness.

\section{Statistical analysis}

The ingredient cost, dispensing fee, VAT and mark-up were extracted for each prescription item. A prescription item refers to the individual item on each claim. Prescriptions are dispensed and claimed monthly and thus an item refers to one month's supply. The HSEPCRS will only reimburse one month's supply in a given claim. Where two different doses of the same drug are dispensed in any month they will be two separate items. Total costs were calculated by summing the ingredient cost, dispensing fee and any VAT or mark-up for each item. Data were aggregated by the scheme under which the items were dispensed, WHO-ATC codes and by each yearly quarter. Mean cost per item was calculated by dividing the total costs by the number of items dispensed. Trends over time were explored. The impacts of two specific cost-containment measures implemented over the study period were assessed using segmented regression analyses of interrupted time series. ${ }^{16}{ }^{17}$ First, we analysed the impact of the increasing GMS co-payments on both GMS and LTI expenditure. We assessed the impact of the increase in co-payment to $€ 1.50$ in the first quarter of 2013 and the subsequent increase to $€ 2.50$ in quarter 4 of 2013. Second, we explored the impact of the introduction of reference pricing. Atorvastatin was the first drug to be subjected to reference pricing. From November 2013, the HSE-PCRS set one price to be reimbursed to pharmacies per each dispensing of atorvastatin. ${ }^{18}$ We omitted the time points before the atorvastatin patent expired in quarter 4, 2011. Multiple linear regression models were fitted, containing a dichotomous variable to assess the level change after the implementation of the intervention and an interaction term between time and the intervention to estimate the change in slope after the intervention was implemented. ${ }^{16} 17$ The most parsimonious models were selected using stepwise elimination.
Model assumptions were checked and autocorrelation was assessed by plotting the residuals and calculating the Breusch-Godfrey test with a null hypothesis of no autocorrelation. ${ }^{16} 17$ The partial autocorrelation function was used to explore if adjustment for seasonality was required. Data management was carried out in SAS V.9.4, data analysis was carried out in R Studio V.3.4.3.

\section{Patient and public involvement}

Patients and the public were not involved in the design or conduct of the study.

\section{RESULTS}

Total prescription costs varied over the study period, peaking at $€ 216994441$ in 2012 (table 1). While the total number of items dispensed increased by $16 \%$, the average cost per item fell from $€ 29.47$ to $€ 25$.40. Diabetes-specific prescription costs increased steadily from $€ 129828301$ in 2011 to $€ 153621478$ in 2015 . During the same period, costs associated with diabetes-related items decreased by $32 \%$ to $€ 50835856$. Between 2011 and 2015, the average cost per item for diabetes-related items reduced from $€ 20.24$ to $€ 12$.41, while average cost per item of diabetesspecific items only decreased from $€ 39.87$ to $€ 38.97$.

\section{Diabetes-specific items}

Over the time period, the greatest increase in costs was observed in blood glucose-lowering drugs (figure 1). Costs rose from $€ 31061768$ in 2011 to $€ 48418540$ in 2015 , accounting for $73 \%$ of the observed increase in total diabetes-specific costs. The total number of blood glucose-lowering drugs dispensed per year increased by 25\% from 1697803 in 2011 to 2115835 in 2015 (online supplemental figure $\mathrm{S} 1$ ). At the start of the study period, insulins and analogues accounted for 32\% of total 


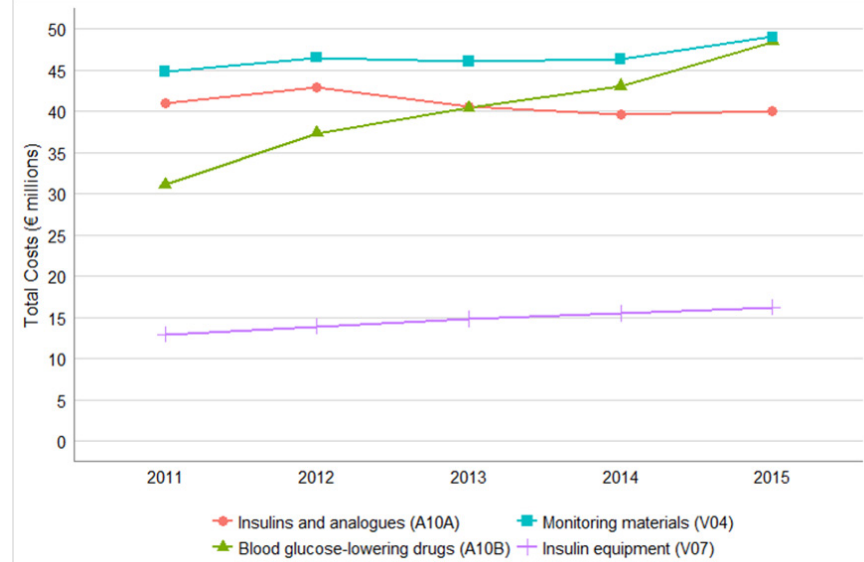

Figure 1 Trends in total costs of diabetes-specific items, 2011-2015.

diabetes-specific costs, with blood glucose-lowering drugs accounting for 24\%. By 2015, blood glucose-lowering drugs had overtaken accounting for $32 \%$ of diabetesspecific costs, with only $20 \%$ of total costs attributable to insulins and analogues. A reduction in the mean cost per item was observed for insulins and analogues (€92.3$€ 79.6$ ), along with a slower rate of increase in the number of items dispensed per year (online supplemental figure S1).

Of the blood glucose-lowering medications, the largest increase in costs was observed for GLP-1 analogues (figure 2). During the study period, the number of items dispensed for GLP-1 analogues increased from 39671 in 2011 to 76181 in 2015 (online supplemental figure S2). The costs attributable to GLP-1 analogues rose from $€ 7438338$ to $€ 13396$ 681, representing an increase of $80 \%$. The number of combination medications dispensed increased by $152 \%$ (76 508 in 2011 to 192590 in 2015) and an increase of $104 \%$ was observed for dipeptidyl peptidase-4 (DDP-4) inhibitors (101952-207809) (online supplemental figure S2). Total costs attributable to

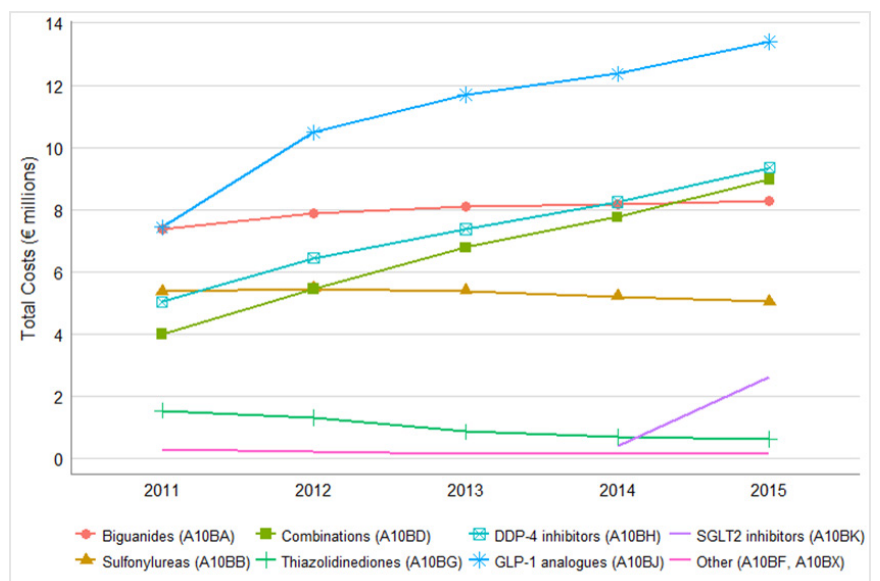

Figure 2 Trends in total costs of blood glucose-lowering drugs, 2011-2015. DDP-4, dipeptidyl peptidase-4; GLP1, glucagon-like peptide-1; SGLT2, sodium-glucose cotransporter 2 .

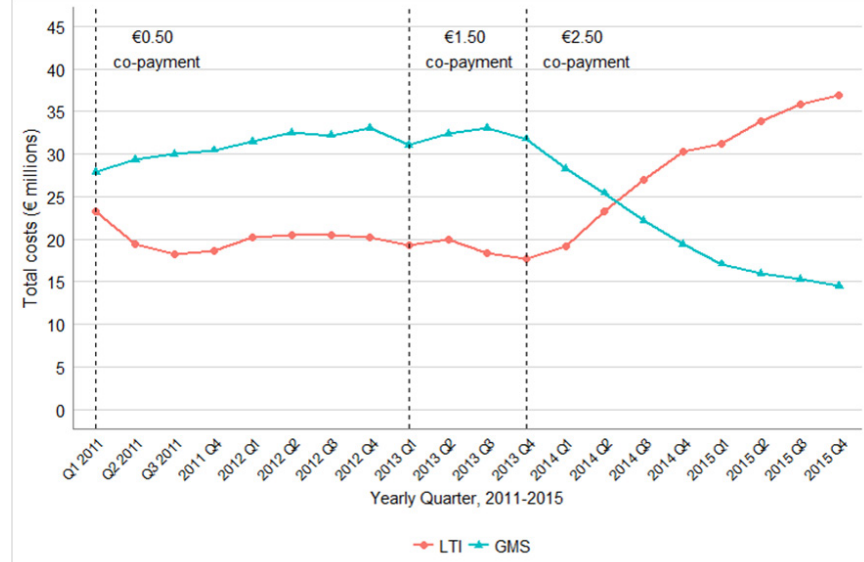

Figure 3 Total costs per yearly quarter, by community scheme, 2011-2015. GMS, General Medical Services; LTI, Long-Term Illness.

combination drugs more than doubled from $€ 4004687$ to $€ 8965514$, while a similar increase from $€ 5035011$ to $€ 9348434$ was observed for DDP-4 inhibitors. While the mean cost of biguanides remained constant over the time period, the number of items dispensed increased gradually from 899148 in 2011 to 1034512 in 2015 (online supplemental figure S2). The costs increased by $€ 1335311$. Between 2014 and 2015, the number of SGLT2 inhibitors dispensed increased by sixfold (9208-55 096) resulting in costs rising from $€ 423118$ to $€ 2615442$.

\section{Diabetes-related items}

Total expenditure on diabetes-related items is stratified by WHO-ATC classification in online supplementary table S2. While the number of lipid-modifying agents dispensed increased by 155989 , the mean cost per item fell from $€ 30.8$ to $€ 13.5$. The total costs of lipid-modifying agents halved from $€ 34225615$ to $€ 17094079$ over the study period.

\section{Impact of cost-containment measures}

The total expenditures (diabetes-specific and diabetesrelated) per yearly quarter for the GMS and LTI schemes are displayed in figure 3. Before the increase in co-payment to $€ 1.50$ in the first quarter of 2013, GMS expenditure was increasing significantly by $€ 694892$ per quarter $(\mathrm{p}=0.001)$. While the increase of the co-payment to $€ 1.50$ did not impact significantly on this trend, expenditure dropped by $€ 2822770$ ( $p=0.03$ ) when the increase was implemented (Q1 2013). The increase in co-payments to $€ 2.50$ resulted in a significant change in slope, with costs reducing by $€ 2968017$ per quarter $(p<0.001)$. There was no significant trend in LTI expenditure before the increase in GMS co-payment to $€ 2.50$. When the GMS co-payments were increased to $€ 2.50$ in quarter 4 of 2013 , there is a statistically significant trend thereafter, with costs now increasing by $€ 2298667$ per quarter $(p<0.001)$.

During the time period, expenditure on atorvastatin fell from $€ 28870808$ to $€ 12609525$. Before reference pricing was introduced, there was a significant decreasing 


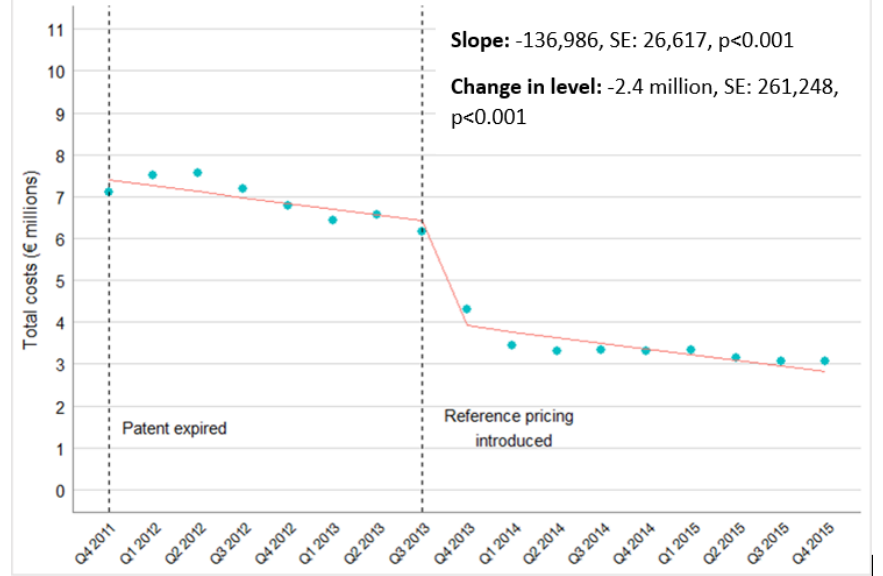

Figure 4 Total costs of atorvastatin per yearly quarter, 2013-2015.

trend of $€ 136986$ per quarter $(\mathrm{p}<0.001)$ (figure 4$)$. Directly after the reference pricing was implemented in the third quarter of 2013, total costs per quarter dropped significantly by $€ 2.4$ million $(\mathrm{p}<0.001)$. There was no evidence of a change in slope after the introduction of reference pricing $(\mathrm{p}=0.2)$.

\section{DISCUSSION}

This study documents the substantial national pharmaceutical expenditure on diabetes and provides an insight into the trends in expenditure patterns over time. Diabetes-specific items account for the majority of expenditure, increasing year on year. By 2015, expenditure reached almost $€ 154$ million, having increased by $18 \%$ since 2011. Conversely, spending on diabetes-related items reduced by $32 \%$ to $€ 51$ million in 2015 . Successful cost-containment measures, such as the introduction of reference pricing for atorvastatin, were largely responsible for the observed cost curtailment.

The steady increase in pharmaceutical expenditure on diabetes-specific items is in line with international trends. ${ }^{419}$ Our findings identify blood glucose-lowering drugs as the primary driver of increasing costs. By 2015, expenditure on blood glucose-lowering drugs had surpassed the costs of insulins and accounted for onethird of all expenditure on diabetes-specific items. This was explained by a sharp increase in the number of items dispensed and also a rise in the mean cost per blood glucose-lowering drug. While the rise in volume of blood glucose-lowering drugs may be explained by increasing prevalence of diabetes over the study period, ${ }^{20}$ guidelines advocating tight glycaemic control combined with the introduction of new classes of blood glucose-lowering medications for dual and triple combination therapy may also contribute to the expedited increase in volume compared with that observed for insulins. ${ }^{72122}$ Similar patterns have been observed across Europe, with insulin use remaining relatively stable in recent years. ${ }^{23-25}$ In the UK, expenditure on blood glucose-lowering drugs now also exceeds the costs of all insulins. ${ }^{19}$ In contrast, over a similar time period in Poland, insulins remained responsible for the majority of expenditure on diabetes-specific items. ${ }^{26}$ This can be explained by reimbursement policies in Poland. For instance, newer drug classes such as DDP-4 inhibitors are not reimbursable due to insufficient evidence on the impact of their long-term use and the high cost per item. ${ }^{26}$

The increasing expenditure on blood glucose-lowering drugs is driven by the increasing volume of newer drug classes; DDP-4 inhibitors, GLP-1 analogues and SGLT2 inhibitors. ${ }^{8}$ For instance, one-third of the increase in expenditure is attributable to GLP-1 analogues. By 2015, GLP-1 analogues accounted for over a quarter $(28 \%)$ of blood glucose-lowering medication costs, despite only representing $3.6 \%$ of items dispensed. Expenditure on SGLT2 inhibitors has risen to over $€ 2$ million in the 1 -year period since their introduction to the market in 2014, suggesting the beginning of a similar trend to that observed for GLP-1 analogues. The most recent international guidelines published by the American Diabetes Association and European Association for the Study of Diabetes advocate for the use of GLP-1 analogues and SGLT2 inhibitors in second line therapy. ${ }^{7}$ Our findings show the impact of the increasing volume of these two drugs classes on pharmaceutical expenditure at a national level and thus raise a concern about how to ensure their accessibility while maintaining affordable and sustainable health systems, particularly in lowerresource settings.

Concern exists about whether the advantages of such blood glucose-lowering drugs outweigh their significantly higher costs. ${ }^{927-29}$ Position statements advocate a patientcentred approach to treatment considering many factors including efficacy, hypoglycaemic risk, impact on weight and cost. ${ }^{730}$ However, with little evidence available on which subgroups of patients may have better outcomes with specific treatments, implementation of such recommendations is challenging. ${ }^{31}$ A large comparative effectiveness study is currently underway, but with results not due until 2020 and with more new drugs in development, an innovative approach is required to ensure the provision of cost-effective diabetes care. ${ }^{31}$

As observed in other OECD countries, our findings support the introduction of reference pricing as a successful mechanism for inducing immediate reductions in expenditure. ${ }^{32}$ The increase of co-payments had a profound impact on the GMS and LTI schemes expenditure, demonstrating the power of moral hazard. All people with diabetes in Ireland are entitled to receive their medications free of charge on the LTI scheme. Prior to the introduction of co-payments, people with diabetes with GMS cover could also receive their medications free of charge through the GMS scheme. Our findings show that the increase in co-payment to $€ 2.50$ per item dispensed under the GMS, resulted in people switching schemes to avail of prescription items free of charge under the LTI scheme. 
This study has a number of strengths. Most noteworthy, we use a large national pharmacy claims database and, as a result, we provide complete and robust data on all diabetes-related pharmaceutical expenditure funded by the Irish government. Cost data from the HSE-PCRS database are highly accurate as its primary function is for reimbursement. ${ }^{14}$ This study provides data on recent pharmaceutical expenditure, allowing us to explore the impact of newer more expensive diabetes medications. There are some important limitations to our study. Due to the absence of clinical diagnoses in the HSE-PCRS database, we make the assumption that anyone receiving items used in the management or treatment of diabetes had a diagnosis of diabetes. This is a sensitive measure. For instance, metformin is also used in the treatment of polycystic ovarian syndrome (PCOS). However, only a small proportion of women of reproductive age are affected by PCOS, with many also having a diabetes diagnosis. ${ }^{33}$ Furthermore, the costs of metformin are low and any effect on total expenditure would be negligible. We estimated costs of items reimbursed for the treatment and management of diabetes as defined by the HSE-PCRS. However, we acknowledge that the sequelae of diabetes are not limited to cardiovascular disease, depression or neuropathy. As a result, our estimates reflect pharmaceutical expenditure on diabetes as defined by the HSE but are an underestimation of the total expenditure attributable to diabetes. It was not possible to identify these costs using HSE-PCRS. In the absence of a unique identifier across reimbursement schemes in our data, it was not possible to determine whether the increase in blood glucose-lowering drugs was due to an increase in the number of people with diabetes or to an increase in the number of people taking a combination of blood glucoselowering medications.

In conclusion, our findings provide timely and stark evidence of the impact of newer drug classes on pharmaceutical expenditure associated with diabetes. Novel blood glucose-lowering drugs classes, DDP-4 inhibitors, GLP-1 analogues and more recently SGLT2 inhibitors, are driving increasing expenditure. Cost-containment measures, namely reference pricing, have resulted in significant savings in expenditure on diabetes-related items used in the prevention and management of diabetes-related complications. However, the increasing cost of blood glucose-lowering medications threatens to negate the effect of these cost-saving interventions and presents a significant challenge for the provision of diabetes care globally. Innovative policies will be required to ensure quality diabetes care can be provided at an equitable, affordable and sustainable rate.

\section{Twitter Kathleen E Bennett @pharmacoepircsi and Patricia M Kearney @trishcork}

Acknowledgements The authors would like to acknowledge the HSE-PCRS and the Department of Pharmacology \& Therapeutics at Trinity College Dublin for access to the data used in this study.

Contributors KNON, KEB and PMK conceived the study design. KEB and KNON accessed and aggregated the data. KNON conducted the literature review and analysed and interpreted the data. APF advised on data analysis. KNON drafted and revised the paper. SMMH, KEB, APF and PMK contributed to the interpretation of the results, revised the paper and approved the final version to be published.

Funding PMK and KNON are funded by a Health Research Board Leader Award (RL/2013/7). KEB is funded by a Health Research Board Leader Award (RL/15/1579).

Competing interests None declared.

Patient consent for publication Not required.

Provenance and peer review Not commissioned; externally peer reviewed.

Data availability statement Data may be obtained from a third party and are not publicly available. The data are administrative pharmacy claims data. The data can be requested from the Health Service Executive Primary Care Reimbursement Service in Ireland.

Supplemental material This content has been supplied by the author(s). It has not been vetted by BMJ Publishing Group Limited (BMJ) and may not have been peer-reviewed. Any opinions or recommendations discussed are solely those of the author(s) and are not endorsed by BMJ. BMJ disclaims all liability and responsibility arising from any reliance placed on the content. Where the content includes any translated material, BMJ does not warrant the accuracy and reliability of the translations (including but not limited to local regulations, clinical guidelines, terminology, drug names and drug dosages), and is not responsible for any error and/or omissions arising from translation and adaptation or otherwise.

Open access This is an open access article distributed in accordance with the Creative Commons Attribution Non Commercial (CC BY-NC 4.0) license, which permits others to distribute, remix, adapt, build upon this work non-commercially, and license their derivative works on different terms, provided the original work is properly cited, appropriate credit is given, any changes made indicated, and the use is non-commercial. See: http://creativecommons.org/licenses/by-nc/4.0/.

ORCID iDs

Kate N 0 Neill http://orcid.org/0000-0003-4843-4265

Kathleen E Bennett http://orcid.org/0000-0002-2861-7665

\section{REFERENCES}

1 Bommer C, Sagalova V, Heesemann E, et al. Global economic burden of diabetes in adults: projections from 2015 to 2030. Diabetes Care 2018;41:963-70.

2 Bommer C, Heesemann E, Sagalova V, et al. The global economic burden of diabetes in adults aged 20-79 years: a cost-of-illness study. Lancet Diabetes Endocrinol 2017;3633:423-30.

3 Zhang P, Gregg E. Global economic burden of diabetes and its implications. Lancet Diabetes Endocrinol 2017;5:404-5.

4 Zhuo X, Zhang P, Kahn HS, et al. Change in medical spending attributable to diabetes: national data from 1987 to 2011. Diabetes Care 2015;38:dc141687.

5 American Diabetes Association. Economic costs of diabetes in the U.S. in 2017. Diabetes Care 2018;41:dci180007.

6 Medicines in Development. Medicines in development for diabetes. Washington, 2016. Available: http://phrma-docs.phrma.org/files/ $\mathrm{dmfile/medicines-in-development-report-diabetes.pdf} \mathrm{[Accessed} 12$ Jun 2018].

7 Davies MJ, D'Alessio DA, Fradkin J, et al. Management of hyperglycemia in type 2 diabetes, 2018. A consensus report by the American diabetes association (ADA) and the European association for the study of diabetes (EASD). Diabetes Care 2018;41:2669-701.

8 Nathan DM. Diabetes: advances in diagnosis and treatment. JAMA 2015;314:1052-62.

9 Qaseem A, Barry MJ, Humphrey LL, et al. Oral pharmacologic treatment of type 2 diabetes mellitus: a clinical practice guideline update from the American College of physicians. Ann Intern Med 2017;166:279-90.

10 Zimmet P, Alberti KG, Shaw J. Global and societal implications of the diabetes epidemic. Nature 2001;414:782-7.

11 Lee I-H, Bloor K, Hewitt C, et al. International experience in controlling pharmaceutical expenditure: influencing patients and providers and regulating industry - a systematic review. J Health Serv Res Policy 2015;20:52-9.

12 OECD. Health at a glance 2015 - How does Ireland compare? 2015. Available: http://www.oecd-ilibrary.org/social-issues-migrationhealth/health-at-a-glance-2009_health_glance-2009-en [Accessed 13 Jun 2018]. 
13 Kenneally M, Walshe V. Pharmaceutical cost-containment policies and sustainability: recent Irish experience. Value Health 2012;15:389-93

14 Sinnott S-J, Bennett K, Cahir C. Pharmacoepidemiology resources in Ireland-an introduction to pharmacy claims data. Eur J Clin Pharmacol 2017;73:1449-55.

15 Health Service Exectutive. Long term illness (LTI) scheme: reference guide as to what is covered in the health service executive for each of the 16 scheduled LTI illnesses, 2016. Available: http://www.hse. ie/eng/services/list/1/schemes/lti/aprovmed/ [Accessed 13 Jun 2018].

16 Wagner AK, Soumerai SB, Zhang F, et al. Segmented regression analysis of interrupted time series studies in medication use research. J Clin Pharm Ther 2002;27:299-309.

17 Bernal JL, Cummins S, Gasparrini A. Interrupted time series regression for the evaluation of public health interventions: a tutorial. Int J Epidemiol 2017;46:348-55.

18 Department of Health. Reference pricing, 2014. Available: https:// health.gov.ie/future-health/reforming-primary-care-2/referencepricing/ [Accessed 13 Jun 2018].

19 Prescribing and medicines team NHS digital. prescribing for diabetes England 2006/07 to 2016/17. Can Med Assoc J 2017:1-24.

20 Tracey ML, Gilmartin M, O'Neill K, et al. Epidemiology of diabetes and complications among adults in the Republic of Ireland 19982015: a systematic review and meta-analysis. BMC Public Health 2016;16:132.

21 McCoy RG, Zhang Y, Herrin J, et al. Changing trends in type 2 diabetes mellitus treatment intensification, 2002-2010. Am J Manag Care 2015;21:e288-96.

22 Inzucchi SE, Bergenstal RM, Buse JB, et al. Management of hyperglycemia in type 2 diabetes, 2015: a patient-centered approach: update to a position statement of the American diabetes association and the European association for the study of diabetes. Diabetes Care 2015;38:140-9.
23 Overbeek JA, Heintjes EM, Prieto-Alhambra D, et al. Type 2 diabetes mellitus treatment patterns across Europe: a population-based Multidatabase study. Clin Ther 2017;39:759-70.

24 Sharma M, Nazareth I, Petersen I. Trends in incidence, prevalence and prescribing in type 2 diabetes mellitus between 2000 and 2013 in primary care: a retrospective cohort study. BMJ Open 2016;6:e010210.

25 Torre C, Guerreiro J, de Oliveira Martins S, et al. Patterns of glucose lowering drugs utilization in Portugal and in the Netherlands. trends over time. Prim Care Diabetes 2015;9:482-9.

26 Śliwczyński A, Brzozowska M, Jacyna A, et al. Drug-class-specific changes in the volume and cost of antidiabetic medications in Poland between 2012 and 2015. PLoS One 2017;12:e0178764:1-11.

27 Palmer SC, Mavridis D, Nicolucci A, et al. Comparison of clinical outcomes and adverse events associated with glucose-lowering drugs in patients with type 2 diabetes: a meta-analysis. JAMA 2016;316:313-24.

28 Lipska KJ, Yao X, Herrin J, et al. Trends in drug utilization, glycemic control, and rates of severe hypoglycemia, 2006-2013. Diabetes Care 2017;40:468-75.

29 Butler PC, Elashoff M, Elashoff R, et al. A critical analysis of the clinical use of incretin-based therapies: are the GLP-1 therapies safe? Diabetes Care 2013;36:2118-25.

30 American Diabetes Association. Standards of medical care in diabetes: pharmacologic approaches to glycemic treatment. Diabetes Care 2017;40:S64-74.

31 Nathan DM, Buse JB, Kahn SE, et al. Rationale and design of the glycemia reduction approaches in diabetes: a comparative effectiveness study (grade). Diabetes Care 2013;36:2254-61.

32 Galizzi MM, Ghislandi S, Miraldo M. Effects of reference pricing in pharmaceutical markets: a review. Pharmacoeconomics 2011;29:17-33.

33 Pate KA. Epidemiology,Diagnosis, and management of polycystic ovary syndrome. Clin Epidemiol 2014;6:1-13. 